\title{
Merlin Expression in Secretory Meningiomas: Evidence of an NF2-independent Pathogenesis?
}

\author{
Immunohistochemical study
}

\author{
Anna Maria Buccoliero, MD, ${ }^{*}$ Chiara Francesca Gheri, MD,* Francesca Castiglione, MD,* \\ Franco Ammannati, MD, $\dagger$ Pasquale Gallina, MD, $\$$ Antonio Taddei, MD, $\S$ \\ Francesca Garbini, MD,* Duccio Rossi Degl'Innocenti, BSc, ${ }^{*}$ Luisa Arganini, MD,* \\ Nicola Di Lorenzo, MD, $\$$ Pasquale Mennonna, MD, $\dagger$ and Gian Luigi Taddei, MD*
}

\begin{abstract}
One of the most common chromosomal regions implicated in the meningiomas tumorigenesis is $22 \mathrm{q} 12$ where the neurofibromatosis 2 (NF2) gene resides. The NF2 tumorsuppressor gene encodes for the merlin/schwannomin protein, which is responsible for the inherited disease neurofibromatosis 2. NF2 gene mutations predominantly occur in transitional and fibroblastic meningiomas, whereas the meningothelial variant is less affected. Secretory meningioma is an infrequent meningioma subtype. Its most typical morphologic feature is the presence of intracytoplasmic or extracytoplasmic round hyaline, eosinophilic, and periodic acid Shiff-positive bodies in a lesion frequently otherwise classifiable as meningothelial meningioma. This study reviews the immunohistochemical merlin expression in 14 consecutive secretory meningiomas. Our purpose was to investigate if secretory meningiomas, analogous to meningothelial meningiomas, follow a molecular route of pathogenesis independent of the neurorofibromatosis 2 gene-associated pathway. All meningiomas showed positive immunocoloration involving the majority of the hyaline inclusions and secretory cells; in $12(86 \%)$ meningiomas, a positive immunoreaction was also documented in nonsecretory tumoral cells. Our results may indicate a molecular, besides morphologic, similarity between secretory and meningothelial meningiomas: the almost constant merlin immunohistochemical expression in our series gives evidence for a possible NF2 gene-independent pathogenesis in secretory meningiomas.
\end{abstract}

Key Words: merlin, NF2, meningioma, secretory, immunohistochemistry

(Appl Immunohistochem Mol Morphol 2007;15:353-357)

Received for publication November 29, 2005; accepted March 29, 2006. From the Departments of *Human Pathology and Oncology; $\ddagger$ Neurosurgery; §General Surgery, University of Florence; and $†$ Unit of Neurosurgery, Careggi Hospital, Florence, Italy.

Reprints: Anna Maria Buccoliero, MD, Department of Human Pathology and Oncology, University of Florence, Viale G.B. Morgagni, 85, 50134 Florence, Italy (e-mail: ambuccoliero@unifi.it). Copyright (C) 2007 by Lippincott Williams \& Wilkins
$M$ eningiomas are frequent primary intracranial neoplasms (about $25 \%$ of all primary tumors in this site) arising from the leptomeningeal covering of the central nervous system. They preferentially affect middleaged and elderly women. Radiation exposure, and hormonal and genetic factors have been implicated in their development and growth. Usually, meningiomas are sporadic, but they may also be a manifestation of the hereditary syndrome neurofibromatosis type 2 (NF2), which is characterized, at the nervous system level, by the development of bilateral vestibular schwannomas, meningiomas, ependymomas, and, occasionally, gliomas and neurofibromas. ${ }^{1-4}$

Meningiomas initiation is linked, both in the NF2associated cases and in the sporadic lesions, to the inactivation of members of the 4.1 superfamily proteins comprised the NF2 gene product merlin/schwannomin. About $60 \%$ of sporadic meningiomas are caused by mutation and/or deletion of the NF2 tumor-suppressor gene on chromosome $22 \mathrm{q} 12$, whereas no causative gene is known for the remaining $40 \% .^{2,5-11}$

Many studies have suggested that merlin is involved in the regulation of cell growth and proliferation. ${ }^{12}$ Nevertheless, the alterations in the merlin functions did not show an incontrovertible prognostic value in meningiomas. Indeed, despite the merlin expression level being reported lower in more malignant meningiomas than in benign meningiomas, the difference does not reach significant levels. ${ }^{6,13,14}$

Meningiomas exhibit a wide range of histologic patterns with numerous classified subtypes (the most recent World Health Organization scheme ${ }^{1}$ recognizes 13 variants) and several uncategorized subtypes. In most cases, histologic variants do not have prognostic significance. However, clear cell, chordoid, papillary, and rhabdoid meningiomas are clinically aggressive. ${ }^{1,15,16}$

Secretory meningioma is an infrequent subtype that accounts for $3 \%$ to $5 \%$. From a clinical point of view, its peculiarities are the frequent insurgence in women at the sphenoid ridge and on frontal convexity $(29 \%$ and $26 \%$, respectively), and the tendency to evoke severe cerebral edema $(40 \%$ to $50 \%)$. At variance with the majority of 
brain tumors where edema is usually associated with more aggressive lesions, edema does not represent a prognostic factor in secretory meningiomas. The most typical morphologic feature is the presence of intracytoplasmic or extracytoplasmic, round hyaline, eosinophilic, and periodic acid Shiff-positive bodies in a lesion frequently otherwise classifiable as meningothelial meningioma. These structures, called pseudopsammoma bodies, are contained in a variable percentage of the neoplastic cells. Characteristically, the pseudopsammoma bodies and the secretory cells immunostain with the carcinoembryonic antigen and with epithelial and secretory markers (ie, keratins, epithelial membrane antigen, IgA, IgM, $\alpha$-1-antitrypsin). In the ultrastructure, the pseudopsammoma bodies are composed of granular and filamentous materials predominantly located in large intracellular lumina lined by microvilli. ${ }^{1,16-24}$

Molecular differences between meningioma subtypes have been reported. Several data provide convincing evidence for supporting an NF2-independent pathogenesis histotype related: the NF2 gene mutations predominantly occur in transitional and fibroblastic meningiomas, whereas the meningothelial variant is significantly less affected. ${ }^{13,25-28}$

This study reviews the immunohistochemical merlin/schwannomin expression of 14 consecutive secretory meningiomas. Our purpose was to preliminarily investigate if secretory meningiomas, analogous to meningothelial meningiomas, follow a molecular route of pathogenesis independent of the NF2 gene-associated pathway.

\section{PATIENTS AND METHODS}

\section{Patients}

Fourteen consecutive secretory meningiomas, surgically treated at the Neurosurgical Service (Careggi Hospital, Florence, Italy) and at the Department of Neurosurgery (University of Florence, Florence, Italy) between January 1993 and June 2005 with available adequate paraffin-embedded specimens entered into the study.

One $(7 \%)$ was a man and $13(93 \%)$ were women. The average age at the time of the surgery was 57 years (range 33 to $97 \mathrm{y}$ ). More often, the tumors were frontal (3 cases, $21 \%$ ) or located at the clivus region (3 cases, $21 \%$ ).

\section{Methods}

The surgical specimens were fixed in $10 \%$ buffered neutral formalin, entirely sampled, and embedded in paraffin. Some 5- $\mu \mathrm{m}$ sections were stained with hematoxylin and eosin (H\&E) and with periodic acid Shiff for the morphologic evaluation. Diagnostic criteria we used were those indicated by the most recently revised World Health Organization classification of tumors of the nervous system. ${ }^{1}$

Further, 5- $\mu \mathrm{m}$ sections of the most representative specimen of each case were mounted on electrostatic slides and used for the immunohistochemical study.
Paraffin sections were heated at 95 to $98^{\circ} \mathrm{C}$ in a waxcapture and antigen-retrieved solution (W-CAP TEC buffer pH 8, Milano, Italy) for 20 minutes. The primary antibody F2-Merlin (rabbit polyclonal-epitope mapping at $\mathrm{NH}_{2}$ terminus, Santa Cruz Biotechnology, Inc.) was used at a dilution of 1:50 at room temperature for 1 hour. Successively, the sections were incubated in a reactive rabbit amplification solution (amplification Kit Ventana Medical System, Tucson, AZ) for 10 minutes at room temperature. Immunoreactivity was detected using a peroxidase-conjugated polymer (ChemMate Dako Envision Detection Kit Peroxidase DAB rabbit-mouse) for 30 minutes followed by 3,3-diaminobenzidine hydrogen as the final indicator for 5 minutes. The nuclei were counterstained with hematoxylin.

Positivity seen at tissue edges was considered artifactual if no tumoral staining was also encountered more centrally; a weak immunocoloration not exceeding that of adjacent structures known to be negative for merlin (ie, collagen) was considered artifactual too.

Merlin expression was evaluated separately in hyaline inclusions/secretory cells and in nonsecretory tumoral cells; it was considered as negative when it was present in not more than $10 \%$ of the neoplastic cells, as (1) when it was present in more than $10 \%$ and within $50 \%$, and as (2) when it was diffuse to more than $50 \%$ of the neoplastic cells. Furthermore, we graded the immunocoloration as + or ++ on the basis of the intensity of staining.

\section{RESULTS}

Secretory features were observed in 13 (93\%) otherwise classifiable meningothelial meningiomas and in $1(7 \%)$ otherwise classifiable transitional meningioma.

All meningiomas that we studied showed positive intense immunocoloration involving the majority of the hyaline inclusions and secretory cells (score $2++$ ). In $12(86 \%)$ meningiomas, a positive immunoreaction was also documented in nonsecretory tumoral cells (score $2+: 8$ cases, $57 \%$; score $2++: 4$ cases, $29 \%$ ); no merlin immunoreaction was appreciable in the nonsecretory tumoral cells in the remaining $2(14 \%)$ meningiomas (score 0$)$.

One of the 2 cases in which the nonsecretory tumoral cells were negative was the only 1 meningioma showing the typical features of the transitional meningioma (Table 1; Fig. 1).

\section{DISCUSSION}

Merlin is a member of the band 4.1 superfamily of proteins. $^{4,8,10,29,30}$ Within this family, merlin shares the highest degree of homology with a group of proteins, including ezrin, radixin, and moesin (ERM proteins) that link the actin cytoskeleton (by an actin-binding region in their $\mathrm{COOH}$ terminus) to cell membrane glycoproteins (by their $\mathrm{NH}_{2}$ terminal residues). The $\mathrm{NH}_{2}$ and $\mathrm{COOH}$ terminal halves of ERM proteins mutually interact intramolecularly to suppress their binding activities. The 
TABLE 1. Secretory Meningiomas

\begin{tabular}{|c|c|c|c|}
\hline \multirow[b]{2}{*}{ Case } & \multirow[b]{2}{*}{ Morphological Background } & \multicolumn{2}{|c|}{ Immunohistochemistry (F2-Merlin Antibody $\mathrm{NH}_{2}$-Terminus Mapping) } \\
\hline & & Hyaline Inclusions/Secretory Cells & Nonsecretory Cells \\
\hline 1 & Meningothelial & $2+$ & $2+$ \\
\hline 2 & Meningothelial & $2++$ & $2+$ \\
\hline 4 & Meningothelial & $2++$ & $2++$ \\
\hline 5 & Meningothelial & $2++$ & $2+$ \\
\hline 6 & Meningothelial & $2++$ & $2++$ \\
\hline 10 & Meningothelial & $2++$ & $2++$ \\
\hline 11 & Meningothelial & $2++$ & - \\
\hline 12 & Meningothelial & $2++$ & $2+$ \\
\hline 13 & Meningothelial & $2++$ & $2+$ \\
\hline 14 & Meningothelial & $2++$ & $2++$ \\
\hline
\end{tabular}

Morphology and immunohistochemistry.

Immunohistochemical score. 0 : negative/not more than $10 \%$ of neoplastic cells, $1:$ more than $10 \%$ and within $50 \%, 2:$ more than $50 \%$ of the neoplastic cells; + : moderate immunostaining; + + : intense immunostaining.

$\mathrm{COOH}$ terminal threonine phosphorylation maintains ERM proteins in the active state by suppressing the intramolecular interaction. ${ }^{4,8,10,31}$

The region of the merlin with the greatest structural similarity to the ERM proteins is the $\mathrm{NH}_{2}$ terminal, twothirds. The $\mathrm{COOH}$ terminus of merlin is unique and lacks the conventional actin-binding region of the ERM proteins (merlin interacts with $\mathrm{F}$-actin through its $\mathrm{NH}_{2}$ terminus). ${ }^{4,8,10,30,32-34}$

Several experimental data demonstrated that the merlin overexpression results in a significant decrease in cell proliferation, reversion of Ras-induced transformation, and reduced tumor formation in nude mice. ${ }^{30-32,35,36}$

The majority of the mutations identified in the NF2 gene results in a truncated protein. ${ }^{27,37-39}$

Conflicting results have been reported with regard to the possible prognostic value of merlin in meningiomas. Several data suggest that merlin loss is relatively equally distributed among clinicopathologic subsets. Indeed, the majority of previous studies indicated NF2 gene inactivation as an early tumorigenic event in sporadic and in NF2-associated meningiomas. ${ }^{6,8,10,13,14,29}$

On the contrary, NF2 gene mutation rates significantly differ between histologic subtypes of meningiomas. ${ }^{5,9,13,14,25,28}$ Earlier, in 1995, Wellenreuther ${ }^{13}$ demonstrated that NF2 gene mutation occurs in $83 \%$ of transitional meningiomas and in $70 \%$ of fibroblastic meningiomas but in only $25 \%$ of meningothelial meningiomas.

Merlin expression may be investigated through several methods. Immunohistochemistry is a simple and relatively nonexpensive method of study and diagnosis. Several antibodies (for fresh and fixed tissue; against $\mathrm{COOH}$ and $\mathrm{NH}_{2}$ terminus) are available to detect merlin. Truncated protein lacks its $\mathrm{COOH}$ terminus. Consequently, antibodies against the $\mathrm{NH}_{2}$ terminus should be considered ineligible to demonstrate alterations in the NF2 gene. Nevertheless, truncated NF2 protein, as a consequence of accelerated degradation possibly mediated by calpain-dependent proteolysis, is unstable. ${ }^{39}$ On this basis we used an antibody against the $\mathrm{NH}_{2}$ terminus (usable on paraffin-embedded tissues) preferring it to the antibody against the $\mathrm{COOH}$ terminus (usable on frozen sections only).

No study investigated the presence of NF2 gene mutations or the merlin expression in secretory meningiomas. Our immunohistochemical results demonstrated that secretory meningiomas, analogous to meningothelial meningiomas, express merlin. Precisely, secretory cells and their hyaline inclusions strongly immunostained in each case, whereas nonsecretory tumoral cells immunostained in all but 2 cases. One of the 2 secretory meningiomas in which the nonsecretory tumoral cells were negative was an otherwise classifiable transitional meningioma. Consequently, we could further suppose that meningothelial meningiomas either in their classical form or in cases with prominent secretory propensity (secretory meningiomas) may arise independently of NF2 gene alterations. Furthermore, the secretory propensity could represent a stigma of the NF2 gene integrity in consideration of the invariable positivity to merlin of secretory tumoral cells in secretory meningiomas. Moreover, pseudopsammoma bodies strongly immunostained in each of our cases, suggesting that merlin could participate in their composition.

In conclusion, our results indicate a possible molecular, besides morphologic, similarity between secretory and meningothelial meningiomas: the almost constant merlin immunohistochemical expression in our series gives evidence for a possible NF2-independent pathogenesis in secretory meningiomas. Further studies on different and large series complete of the follow-up are necessary to ascertain the possible consequence of the presence or absence of merlin alterations in meningothelial and secretory meningiomas and in other meningiomas. 

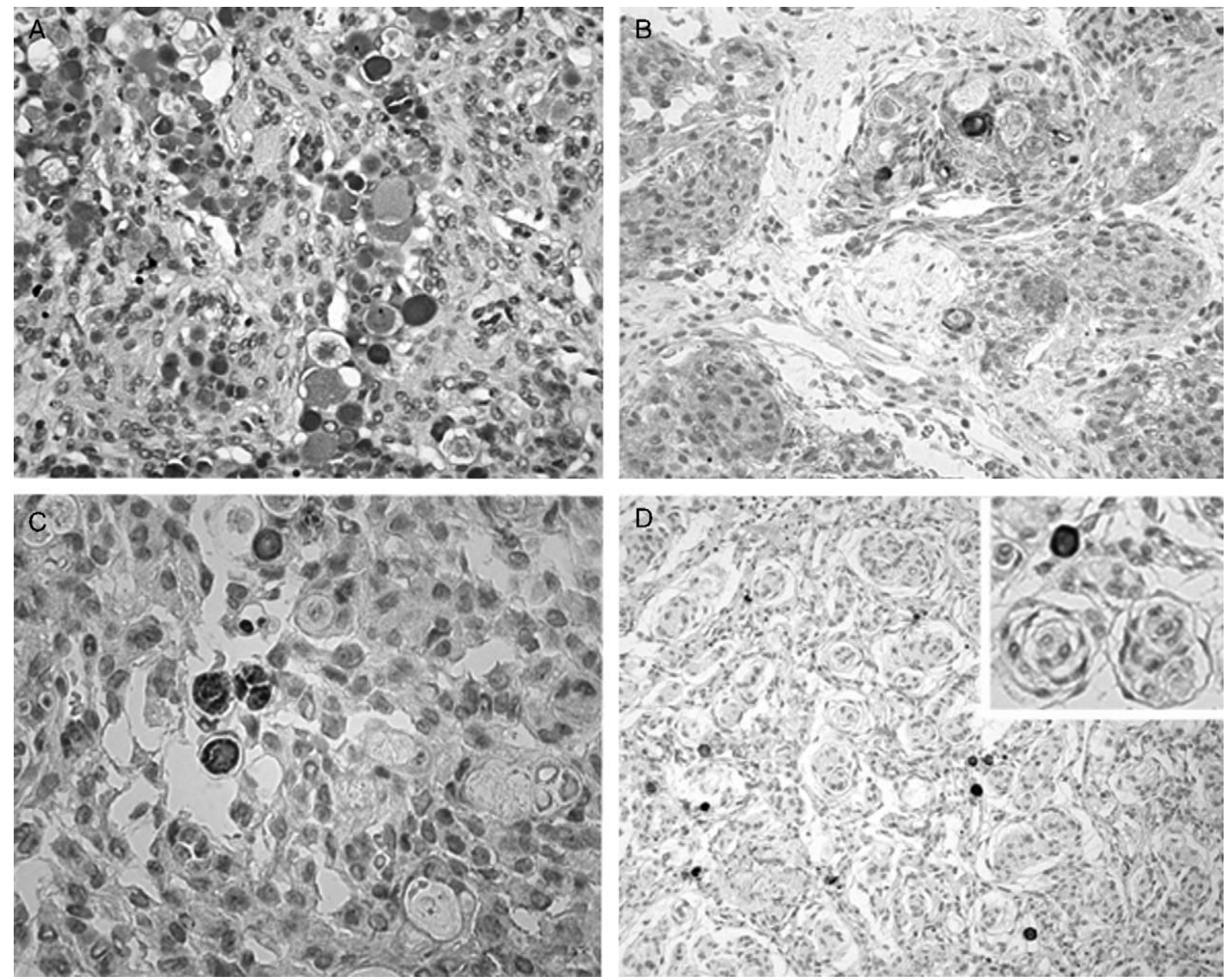

FIGURE 1. Periodic acid Shiff-positive hyaline inclusions (A). Intense and diffuse immunostaining both in the hyaline inclusions/ secretory cells and in the nonsecretory tumoral cells, score 2++ (B). Diffuse positivity both in the hyaline inclusions/secretory cells (intense staining), score $2++$, and in the nonsecretory tumoral cells (moderate staining), score $2+(C)$. Intense and diffuse immunostaining in hyaline inclusions/secretory cells, score 2++; negative nonsecretory tumoral cells (D; case 2 Table 1). Original magnification (A-D) $200 \times$; inset (D): $400 \times$.

\section{REFERENCES}

1. Louis DN, Scheithauer BW, Budka H, et al. Meningiomas. In: Kleihues P, Cavenee K, eds. World Health Organization Classification of Tumors. Pathology and Genetics of Tumours of the Nervous System. Lyon: IARC Press; 2000.

2. De Vitis LR, Tedde A, Vitelli F, et al. Screening for mutations in the neurofibromatosis type 2 (NF2) gene in sporadic meningiomas. Hum Genet. 1996;97:632-637.

3. Evans DGR, Huson SM, Donnai D, et al. A genetic study of type 2 neurofibromatosis in the United Kingdom. Prevalence, mutation rate, fitness and confirmation of maternal transmission effect on severity. J Med Genet. 1992;29:841-846.

4. Gutmann DH. The neurofibromatoses: when less is more. Hum Mol Genet. 2001;10:747-755.

5. Perry A, Gutmann DH, Reinfenberger G. Molecular pathogenesis of meningiomas. J Neuro-Oncol. 2004;70:183-202.

6. Perry A, Cai DX, Sheithauer B, et al. Merlin, DAL-1, and progesterone receptor expression in clinicopathologic subsets of meningioma: a correlative immunohistochemical study of 175 cases. J Neuropathol Exp Neurol. 2000;10:872-879.

7. Luis E, Gutman DH. Meningioma: an update. Curr Opin Neurol. 2004:17:687-692
8. Robb VA, Li W, Gascard P, et al. Identification of a third protein 4.1 tumor suppressor, protein $4.1 \mathrm{R}$, in meningioma pathogenesis. Neurobiol Dis. 2003;13:191-202.

9. Ueki K, Wen-Bin C, Narita Y, et al. Tight association of loss of merlin expression with loss of heterozygosity at chromosome 22q in sporadic meningiomas. Cancer Res. 1999;59:5995-5998.

10. Gutmann DH, Donahoe J, Perry A, et al. Loss of DAL-1, a protein 4.1-related tumor suppressor, is an important early event in the pathogenesis of meningiomas. Hum Mol Genet. 2000;10:1495-1500.

11. Gutmann DH, Giordano MJ, Fishback AS, et al. Loss of merlin expression in sporadic meningiomas, ependymomas and schwannomas. Neurolol. 1997;49:267-270.

12. McClatchey AI, Giovannini M. Membrane organization and tumorigenesis - the NF2 tumor suppressor, merlin. Genes Dev. 2005; 19:2265-2277.

13. Wellenreuther R, Kraus JA, Lenartz D, et al. Analysis of the neurofibromatosis 2 gene reveals molecular variants of meningiomas. Am J Pathol. 1995;146:827-832.

14. Perry A, Giannini C, Raghavan R, et al. Aggressive phenotypic and genotypic features in pediatric and NF-2 associated meningiomas: a clinicopathologic study of 53 cases. J Neuropathol Exp Neurol. 2001;10:994-1003. 
15. Caldarella A, Buccoliero AM, Marini M, et al. Oncocytic meningioma: a case report. Pathol Res Pract. 2002;198:109-113.

16. Buccoliero AM, Caldarella A, Taddei A, et al. Atypical, anaplastic and unusual meningiomas. Morphology and incidence in 300 consecutive cases. Pathologica. 2003;95:83-87.

17. Kepes JJ. The fine structure of hyaline inclusions (pseudopsammoma bodies) in meningiomas. $J$ Neuropathol Exp Neurol. 1975;34:282-294.

18. Budka H. Hyaline inclusions (pseudopsammoma bodies) in meningiomas: immunocytochemical demonstration of epithelial-like secretion of secretory component and immunoglobulins A and $\mathrm{M}$. Acta Neuropathol. 1982;56:294-298.

19. Alguacil-Garcia A, Pettigrew NM, Sima AAF. Secretory meningioma. A distinct subtype of meningioma. Am J Surg Pathol. 1986;10:102-111.

20. Ejeckam GC, Azadeh B, Hamad A. Secretory meningioma. Histopathol. 1992;21:475-477.

21. Ide M, Jimbo M, Yamamoto M, et al. MIB-1 staining index and peritumoral brain edema of meningiomas. Cancer. 1996;78:133-143.

22. Probst-Cousin S, Villagran-Lillo R, Lahl R, et al. Secretory meningioma. Clinical histologic, and immunohistochemical findings in 31 cases. Cancer. 1997;79:2003-2015.

23. Çolakoálu N, Demirta ${ }^{\circ}$ E, Oktar N, et al. Secretory meningiomas. Report of clinical, immunohistochemical findings in 12 cases and review of literature. $J$ Neuro-Oncol. 2003;62:233-241.

24. Ironside JW, Moss TH, Louis DN, et al. Diagnostic Pathology of Nervous System Tumours. London: Churchill Livingstone; 2002.

25. Wellenreuther R, Waha A, Vogel Y, et al. Quantitative analysis of neurofibromatosis type 2 gene transcript in meningiomas supports the concept of distinct molecular variants. Lab Invest. 1997;6: 601-606.

26. Hitotsumatsu $T$, Iwaki $T$, Kitamoto $T$, et al. Expression of neurofibromatosis 2 protein in human brain tumors: an immunohistochemical study. Acta Neuropathol (Berlin). 1997;93:225-232.

27. Lee JH, Sundaram V, Stein DJ, et al. Reduced expression of schwannomin/merlin in human sporadic meningiomas. Neurosurgery. 1997;40:578-587.

28. Evans JJ, Jeun SS, Lee JH, et al. Molecular alterations in the neurofibromatosis type 2 gene and its protein rarely occurring in meningothelial meningiomas. J Neurosurg. 2001;94:111-117.
29. Kalamarides M, Niwa-kawakita M, Leblois H, et al. NF2 gene inactivation in arachnoidal cells is rate-limiting for meningioma development in mouse. Gene Dev. 2002;16:1060-1065.

30. Grönholm M, Teesalu T, Tyynelä J, et al. Characterization of the NF2 protein merlin and the ERM protein ezrin in human, rat, and mouse central nervous system. Mol Cell Neurosci. 2005;28:683-693.

31. Rangwala R, Banine F, Borg JP, et al. Erbin regulates mitogen activated protein (MAP) kinase activation and MAP kinasedependent interactions between merlin and adherens junction protein complexes in schwann cells. $J$ Biol Chem. 2005;280: $11790-11797$.

32. James MF, Manchanda N, Gonzalez-Agosti C, et al. The neurofibromatosis 2 protein product merlin selectively binds F-actin but not G-actin, and stabilizes the filaments through a lateral association. Biochem J. 2001;356:377-386.

33. Stemmer-Rachamimov AO, Gonzalez-Agosti C, Xu L, et al. Expression of NF2-encoded merlin and related ERM family proteins in the human central nervous system. $J$ Neuropathol Exp Neurol. 1997;56:735-742.

34. James MF, Manchanda N, Gonzalez-Agosti C, et al. The neurofibromatosis 2 protein product merlin selectively binds F-actin but not G-actin, and stabilizes the filaments through a lateral association. Biochem J. 2001;356:377-386.

35. Chen Y, Gutman DH, Haipek CA, et al. Characterization of chicken NF2/merlin indicates regulatory roles in cell proliferation and migration. Dev Dynam. 2004;229:541-554.

36. Lallemand D, Curto M, Saotome I, et al. NF2 deficiency promotes tumorigenesis and metastasis by destabilizing adherens junctions. Genes Dev. 2003;17:1090-1100.

37. Stemmer-Rachamimov $\mathrm{AO}, \mathrm{Xu} \mathrm{L}$, Gonzalez-Agosti C, et al. Universal absence of merlin, but not other ERM family members in schwannomas. Am J Pathol. 1997;151:1649-1654.

38. Gutmann DH, Geist RT, Xu HM, et al. Defect in neurofibromatosis 2 protein function can arise at multiple levels. Hum Mol Genet. 1998; 7:335-345.

39. Den Bakker MA, van Tilborg AAG, Kros JM, et al. Truncated NF2 proteins are not detected in meningiomas and schwannomas. Neuropathology. 2001;21:168-173. 